\title{
Sequential changes in plasma lipoproteins and body fat composition during polyunsaturated fat feeding in man
}

\author{
BY J.SHEPHERD, JENNIFER M. STEWART, JANICE G. CLARK AND \\ KAY CARR* \\ Departments of Biochemistry and Dietetics, ${ }^{*}$ \\ Royal Infirmary, Glasgow $G_{4}$ OSF
}

(Received 26 March 1980 - Accepted 4 June 1980)

\begin{abstract}
I. The early effects of a moderate polyunsaturated fat diet on the composition of circulating lipoproteins and adipose tissue fatty acids were measured in five healthy adults.

2. The fatty acid content and gross composition of the three major plasma lipoprotein fractions altered within $7 \mathrm{~d}$ of treatment. The response of depot fat was slower but did show a significant and progressive change after $14 \mathrm{~d}$ on the diet.

3. The efficiency of the moderate diet in changing the composition of the lipoproteins suggests that it should be equally effective in altering their metabolic handling.
\end{abstract}

Substitution of polyunsaturated for saturated fat in the human diet causes profound changes in the chemical composition (Kayden et al. 1963; Spritz \& Mishkel, 1969) and physical properties (Morrisett et al. 1977) of the plasma lipoproteins which become apparent within $6-8 \mathrm{~h}$ of diet modification (Kayden et al. 1963) and are complete by $14 \mathrm{~d}$ (Spritz \& Mishkel, 1969). These changes have important effects on lipoprotein metabolism. In an earlier series of studies we have shown that ingestion of a highly polyunsaturated fat diet promotes the catabolism of plasma low-density lipoproteins (LDL) and reduces the rate of synthesis of the major high-density-lipoprotein (HDL) apoprotein, apolipoprotein A-I (Shepherd et al. 1978; Shepherd et al. 1980). The present report extends our observations on this therapeutic regimen by examining the sequential changes which a more moderate diet produces over a $35 \mathrm{~d}$ period in the composition of the plasma lipoproteins and the fatty acid content of human adipose tissue.

\section{METHODS}

\section{Subjects}

Five healthy adult females (aged 20-22 years) were studied. None had clinical or biochemical evidence of cardiac, hepatic, renal or endocrine disease. No medications were given for 4 weeks before and throughout the study.

\section{Diets}

All subjects were instructed to describe, weigh and record their daily food intake over a $7 \mathrm{~d}$ period, and were supplied with dietary scales and fluid measures to achieve more accuracy wherever possible. This information was used to calculate (Table I) the average daily energy consumption of each subject as protein, carbohydrate, polyunsaturated fats and other fats (Paul \& Southgate, 1978). An energetic diet of higher polyunsaturated fat content was then prepared for each subject by substitution of as much safflower seed oil for saturated fat as was consistent with palatability. The percentage of dietary energy as carbohydrate, fat and protein was maintained as in the preliminary study (Table I). This involved eating 
Table I. Compositions of control and polyunsaturated fat diets eaten by five normal adult female subjects

\begin{tabular}{|c|c|c|c|c|c|c|c|}
\hline \multirow{2}{*}{$\begin{array}{c}\text { Subject } \\
\text { no. }\end{array}$} & \multirow{2}{*}{$\begin{array}{l}\text { Mean daily } \\
\text { energy intake } \\
\text { (MJ) }\end{array}$} & \multicolumn{4}{|c|}{ Energy intake $(\%)$ as: } & \multicolumn{2}{|c|}{$\begin{array}{l}\text { Polyunsaturated fat: } \\
\text { saturated fat }\end{array}$} \\
\hline & & Protein & Carbohydrate & Ethanol & Fat & Control diet & Test diet \\
\hline $\mathbf{I}$ & $9 \cdot 68$ & 13 & 39 & 5 & 43 & 0.14 & I.96 \\
\hline 2 & 6.46 & 19 & 46 & I & 34 & 0.47 & I'II \\
\hline 3 & $8 \cdot 73$ & 10 & 42 & 3 & 45 & $0 \cdot 16$ & 2.00 \\
\hline 4 & $6 \cdot 20$ & 21 & 48 & 3 & 28 & 0.16 & $1 \cdot 88$ \\
\hline 5 & 8.99 & 12 & 40 & o & 48 & 0.12 & 1.64 \\
\hline
\end{tabular}

the same foods each day excepting fruit, lean meat and vegetables which were provided on exchange lists to give variety. The polyunsaturated diet maintained the mean bodyweight of each subject within $2.0 \%$ of the starting value throughout the $35 \mathrm{~d}$ of the study.

\section{Sample handling}

Before beginning the diet, and on days 7, 14, 21 and 35 of diet therapy, a $50 \mathrm{ml}$ plasma sample and $50 \mathrm{mg}$ (approximately) adipose tissue biopsy was collected from each subject following a $14 \mathrm{~h}$ fast and analysed as described later.

\section{Plasma analysis}

Very-low-density lipoproteins (VLDL), LDL and HDL (densities (g/l); 0.95-r.006, $\mathrm{I} \cdot 006-\mathrm{I} \cdot 063$ and $\mathrm{I} \cdot 063-\mathrm{I} \cdot 2 \mathrm{I}$ respectively) were isolated by sequential ultracentrifugation as described by Havel et al. (1955) and purified by a further wash as their upper limit density. The chemical composition of each fraction was then determined by estimation of free and esterified cholesterol (Boehringer Cholesterol Kit 15732, Boehringer Mannheim Biochemicals, Mannheim, West Germany), triglyceride (Boehringer Triglyceride Kit I260I2), phospholipid (Bartlett, 1959) and protein (Lowry et al. 1951). Finally, a portion of each fraction was extracted with organic solvents and subjected to fatty acid analysis (Morrisett et al. 1977) by gas-liquid chromatography.

\section{Adipose tissue analysis}

Subcutaneous adipose tissue biopsies were removed at weekly intervals from the abdominal wall of each subject through $5 \mathrm{~mm}$ incisions made alternately on the right and left side midway between the anterior superior iliac spine and the umbilicus. The specimens were hydrolysed by treatment with $\mathrm{I} \cdot \mathrm{O} \mathrm{M}$-methanolic sodium hydroxide for $30 \mathrm{~min}$ at $100^{\circ}$ and the liberated fatty acids esterified using I $40 \mathrm{~g}$ boron trifluoride/ 1 methanol and analysed by gas-liquid chromatography (Morrisett et al. 1977).

\section{Statistical analysis}

Comparisons of lipoprotein and adipose tissue compositions before and after institution of the polyunsaturated fat diet were made by paired Student's $t$ test.

\section{Ethical considerations}

Each volunteer gave informed consent to the project which was in accord with the principles of the Ethical Committee of the Royal Infirmary, Glasgow.

\section{RESULTS}

\section{Lipoprotein compositions}

Ingestion of the polyunsaturated-fat diet produced rapid and significant changes in the compositions of the circulating lipoproteins of all subjects (Tables 2, 3 and 4). 
Polyunsaturated fat diets and tissue lipids

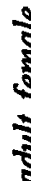

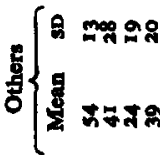

ปั้

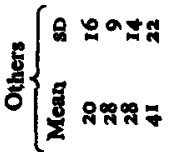

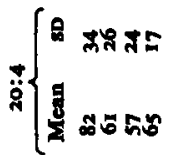

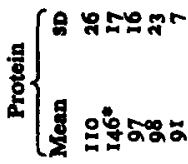

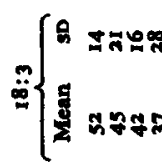

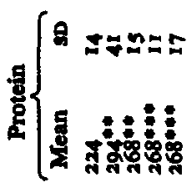

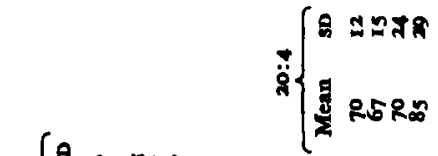

हैं

8

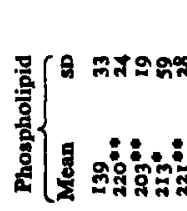

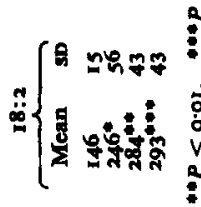

है

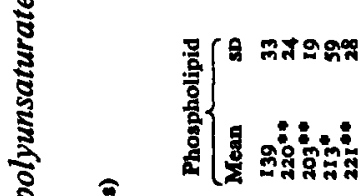

蛋

:

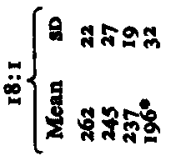

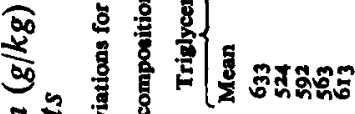

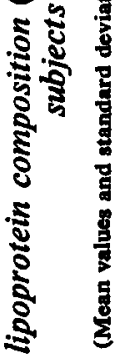

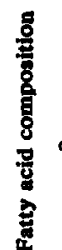

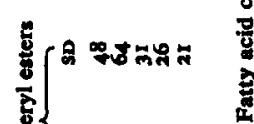

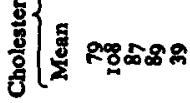

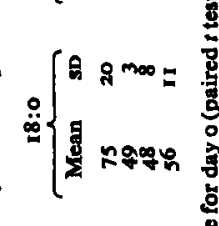

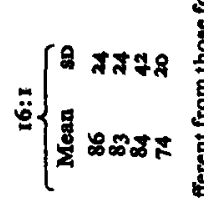

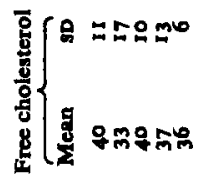

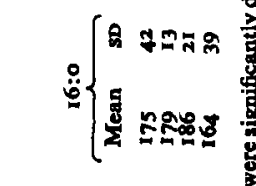

鄫

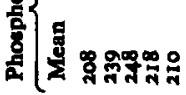

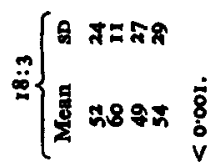

కับ

है

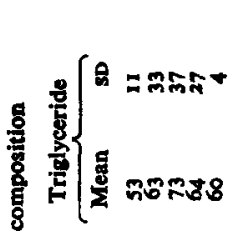

$\frac{2}{8}$

$\frac{8}{30}$

ปั๊

क्ष

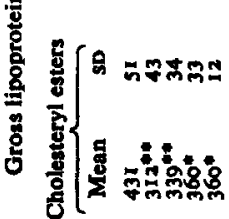

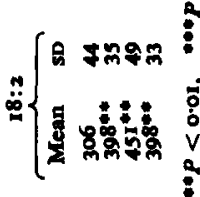

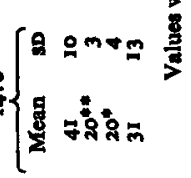

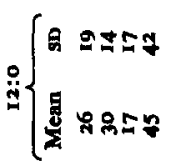

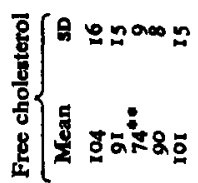

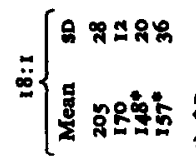

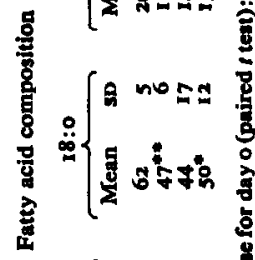

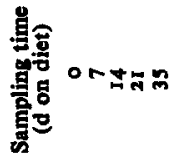

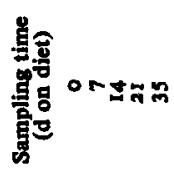

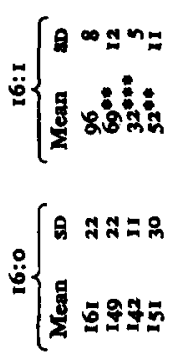

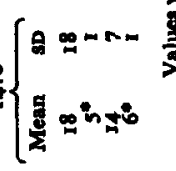

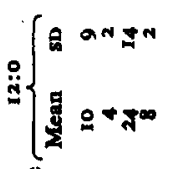

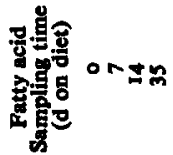

㩆尊

竞

峁 
है
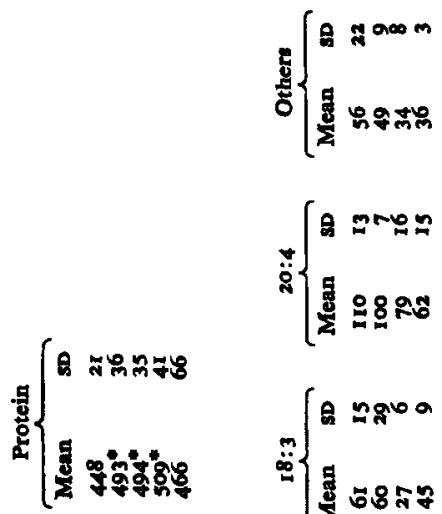

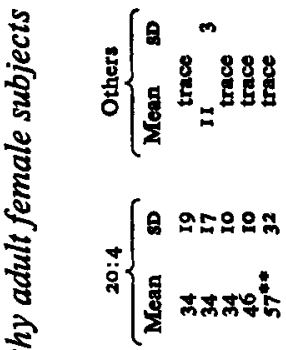

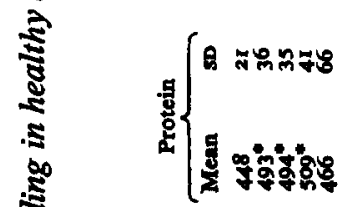

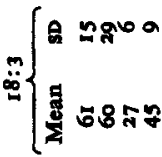

壱

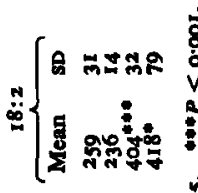

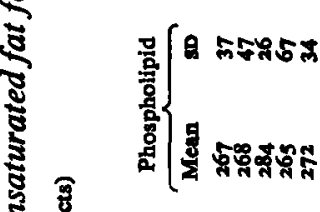

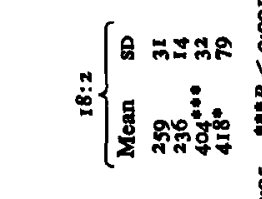

5

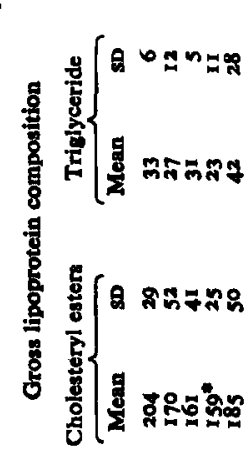

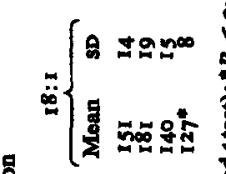

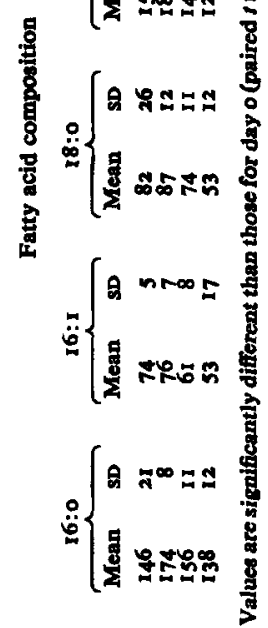

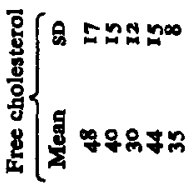

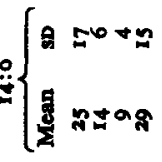

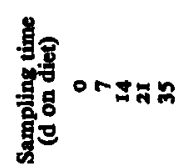
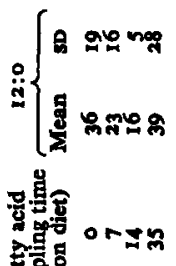

एँ

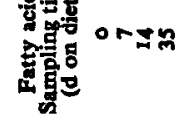

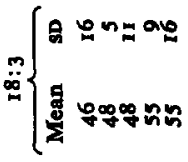

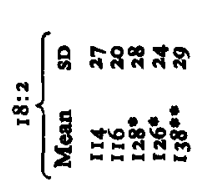
悉

8

8

o $\theta \pm 0 \pm n z$

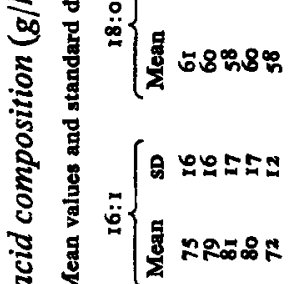

旁

范

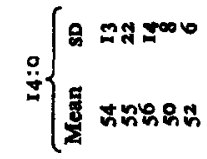

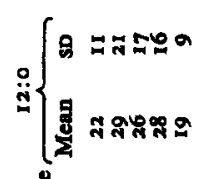

ऊ 
In VLDL (Table 2) the percentage of fatty acid 18:2 rose within $7 \mathrm{~d}$ from a control value of $14.6 \pm 1.5$ (mean \pm I SD) to $24.6 \pm 5.6(P<0.05)$ and reached a maximum of $29.3 \pm 4.3(P<0.00 \mathrm{I})$ by day 35 (Table 2$)$. This increment was associated with reciprocal changes in more saturated fatty acids. Specifically, the level of the most abundant fatty acid in this lipoprotein, $18: \mathrm{I}$, fell from $26.2 \pm 2.2$ to $19.6 \pm 3.2 \%(P<0.05)$ over the $35 \mathrm{~d}$ of diet therapy. Similar smaller reductions were also seen in 14:0, 16:1 and 18:0 although in the instance of the last two, statistical significance was not reached. Alterations in the over-all composition of VLDL accompanied these changes in fatty acid content and primarily affected the hydrophilic, phospholipid-rich surface coat of the particles. The percentage phospholipid rose from $13.9 \pm 3.3$ to a maximum of $22.1 \pm 2.8$ by day 35 $(P<0.01)$. There was no concomitant reduction in the percentage of core components (cholesterol, cholesteryl esters and triglyceride) in the fraction.

LDL (Table 3) showed the greatest compositional change in response to polyunsaturated fat ingestion. Again, the largest increment in over-all fatty acid composition was seen in the 18:2 fraction which rose from a control value of $30.6 \pm 4.4$ of the total fatty acid content to a maximum of $45.1 \pm 4.9 \%(P<0.01)$ by day 14 (Table 3$)$. A fall in the percentage of $14: 0,16: 0,18: 0$ and $18: 1$ accompanied this rise.

Major structural alterations also affected the LDL fraction as a result of the treatment (Table 3). In particular, the percentage of cholesteryl esters fell from $43 \cdot I \pm 5 \cdot I$ to $3 I \cdot 2 \pm 4 \cdot 3$ $(P<0.01)$ by day 7 and stabilized at $36 \cdot 0 \pm I \cdot 2$ at day 35 . In parallel with this reduction in core components there was an increase $(P<0.001)$ in the percentage protein in the fraction. Consequently, the polyunsaturated diet produced a significant decrease in cholesterol:protein in LDL, in keeping with the proposal that the mean particle diameter had fallen during treatment. This factor, calculated by the method of Shen et al. (1977), was $I 92 \AA$ on day 0 and fell to $167 \AA$ by day 35 .

The fatty acid spectrum in HDL, (Table 4 ) like those of the other major plasma lipoprotein fractions, was significantly influenced by diet therapy. The percentage of fatty acid 18:2 again rose during treatment (from $25.9 \pm 3.1$ to $41.8 \pm 7.9 ; P<0.05$ ) at the expense of the more saturated fatty acids (Table 4). Although there was a consistent reduction in $16: 0,16: 1,18: 0$ and $18: 1$, this only reached significance in the instance of the latter. These changes again reflect the fatty acid composition of the diet. Over all, the effects of the diet on HDL composition were minimal (Table 4) and were largely confined to the protein component of the particle which showed an increase from 44.8 to a mean maximal value of 50.9 on day 21 .

\section{Adipose tissue fatty acid compositions}

The response of adipose tissue to the $35 \mathrm{~d}$ of diet modification was much less than that of the lipoproteins (Table 5). Again, however, the changes reflected the dietary fat composition. After 2 weeks' treatment there was a small but significant increase in the percentage of fatty acid 18:2 which rose to a maximum by day 35 . Fatty acid $20: 4$ also rose significantly after 5 weeks treatment. These increments seemed to occur at the expense of the more saturated fatty acids although only that fall apparent in $18:$ I was statistically significant.

\section{DISCUSSION}

In two earlier studies we examined the influence of polyunsaturated-fat diets on the chemical composition and metabolism of HDL (Shepherd et al. 1978) and LDL (Shepherd et al. 1980). We intentionally used a diet which was an extreme example of that normally employed in clinical practice in order to maximize its perturbative effect on the lipoproteins. This diet did not take palatability into account and is unlikely to be acceptable to most patients as 
long-term therapy. The present study was designed to determine whether our previous findings still apply when a more acceptable, less extreme diet is used.

Our results indicate that whereas the relative abundance and saturation level of fat in the diet of normal individuals shows substantial variation (cf. subjects nos. 2 and 5 ,Table I), it is possible by limited manipulation of this dietary component alone to cause significant changes in the chemical composition of the circulating lipoproteins. Further, these changes agree qualitatively with the results produced by extreme diet modification, inasmuch as both the fatty acid saturation level and the gross chemical composition of the lipoproteins are affected. Since these two factors contribute to the microscopic fluidity of the lipoproteins, it is not surprising that dietary manipulations of the type described here should be accompanied by an increase in the fluidity of the particles (Morrisett et al. 1977; Shepherd et al. 1978), providing a rational explanation for the changes in lipoprotein metabolism which accompany polyunsaturated fat feeding (Shepherd et al. 1978; Shepherd et al. 1980).

Safflower seed oil, the source of dietary polyunsaturated fatty acids used in this study, contained $(\mathrm{g} / \mathrm{kg}) 670 \mathrm{18}: 2, \mathrm{I} 60 \mathrm{18}: \mathrm{I}, 80 \mathrm{I}$ 16:0 and trace amounts of other fatty acids on gasliquid chromatographic analysis. The effects which it produced on the fatty acid content of the circulating lipoproteins reflects this composition. In all lipoprotein fractions I8:2 was most affected by treatment; and the increment which it exhibited was consistently associated with a reduction in fatty acid $\mathrm{I} 8: \mathrm{I}$.

The changes which occurred in lipoprotein composition were qualitatively similar to those reported for LDL and HDL during administration of the extreme diet. The LDL fraction became depleted in cholesterol and relatively enriched in protein, so that the cholesterol:protein fell as a result of treatment. The phospholipid content of the particle rose, but did not reach the level of significance observed previously (Shepherd et al. 1980). The diet-induced alteration in HDL composition was confined to an enrichment of its protein content. This contrasts with the fall in protein and increase in phospholipid reported during administration of the extreme diet (Shepherd et al. 1978). The measured increase in VLDL phospholipid during polyunsaturated fat administration suggests that the diet may have caused a fundamental change in the structure of these particles. Since phospholipid constitutes a major component of the surface coat of the lipoprotein, its enrichment is in accord with the proposal that the mean particle diameter is reduced during treatment. In fact its calculated value (from Shen et al. 1977) fell from $382 \AA$ on day $\circ$ to $330 \AA$ by day 35 .

It is now well established that the composition of human adipose tissue is influenced by diet (Miettinen et al. 1972). It is also appreciated that the response of adipose tissue to diet modification is substantially delayed, in contrast to changes in blood lipids, and varies with sampling site (Pittet et al. 1979). By sampling from a fixed location on the anterior abdominal wall we have shown (Table 5) that although the diet-induced change in fatty acid composition of the adipose tissue biopsy is slow, measurable effects become increasingly apparent after $14 \mathrm{~d}$ of treatment. These first involve an enrichment of $18: 2$ in the fat stores with displacement of $18: 1$. Consequently, in adipose tissue and in circulating lipoproteins, I8: I behaves more like a saturated than an unsaturated fatty acid.

The author acknowledges the excellent secretarial assistance of Ms Annette Paterson. 


\section{REFERENCES}

Bartlett, G. R. (1959). J. biol. Chem. 234, 466.

Havel, R. J., Eder, H. A. \& Bragdon, J. H. (1955). J. clin. Invest. 39, 1345.

Kayden, H. J., Karmen, A. \& Dumont, A. (1963). J. clin. Invest. 42, 1373.

Lowry, O. H., Rosebrough, N. J., Farr, A. L. \& Randall, R. J. (195I). J. biol. Chem. 193, 265.

Miettinen, M., Turpeinen, O., Karvonen, M. J., Elobuo, R. \& Paavilainen, E. (1972). Lancet ii, 835.

Morrisett, J. D., Pownall, H. J., Jackson, R. L., Segura, R., Gotto, A. M. \& Taunton, O. D. (1977). In Polyunsaturated Fatty Acids, p. 139. [R. T. Wolman and W. H. Kunan, editors]. Am. Oil Chem. Soc. Monogr. no. 4. Champaign, Ill: ADCS Publishers.

Paul, A. A. \& Southgate, D. A. T. (1978). McCance and Widdowson's The Composition of Foods, 4th ed. Amsterdam: Elsevier/North Holland Biomedical Press.

Pittet, Ph. G., Halliday, D. \& Bateman, P. E. (1979). Br. J. Nutr. 42, 57.

Shen, B. W., Scanu, A. M. \& Kezdy, F. J. (1977). Proc. Natl Acad. Sci. U.S.A. 74, 837.

Shepherd, J., Packard, C. J., Grundy, S. M., Yeshurun, D., Gotto, A. M. \& Taunton, O. D. (I980). J. Lipid Res. $21,91$.

Shepherd, J., Packard, C. J., Patsch, J. R., Gotto, A. M. \& Taunton, O. D. (1978). J. clin. Invest. 61 , 1582.

Spritz, N. \& Mishkel, M. A. (I969). J. clin. Invest. 48, 78. 